\section{Nodal activity in the node governs left-right asymmetry}

\author{
Jane Brennan, ${ }^{1}$ Dominic P. Norris, ${ }^{2}$ \\ and Elizabeth J. Robertson ${ }^{3}$ \\ Department of Molecular and Cellular Biology, \\ Harvard University, The Biological Laboratories, \\ Cambridge, Massachusetts 02138, USA
}

Nodal is expressed at the lateral edges of the mouse node, but its function in this "organizer" tissue remains unknown due to the early lethality of Nodal mutant embryos. Here we used a genetic strategy to selectively remove Nodal activity from the node. Embryos lacking Nodal in the node fail to initiate molecular asymmetry in the left lateral plate mesoderm and exhibit multiple left-right patterning defects. Nodal may also act as a short-range signal to establish a functional midline barrier. Our findings confirm that the mouse node is instrumental in initiating left-right axis specification and identify Nodal as the key morphogen regulating this process.

Received June 18, 2002; revised version accepted August 1, 2002.

Genetic pathways controlling invariant situs of the major internal organ systems have been described in several vertebrate model systems (for review, see Capdevila et al. 2000; Hamada et al. 2002). In all cases, expression of the TGF- $\beta$ signaling molecule, Nodal, is restricted to the left side of the embryonic axis, where its activity is critical for specifying the embryonic left-right (LR) axis. The upstream cellular and molecular mechanisms that direct asymmetric gene expression have been extensively described in chick. However, relatively little is known about how embryonic symmetry is broken, and how the LR signaling cascade that ultimately controls the positioning and morphogenesis of the internal organs is activated in mammalian embryos.

The mouse node is a bilaminar structure found at the rostral end of the primitive streak and has equivalent secondary axes inducing properties as Spemann's organizer in Xenopus (for review, see Beddington and Robertson 1999). It consists dorsally of epiblast and ventrally of the most caudal aspect of the notochordal plate. Several recent studies indicate that the mouse node plays an important role in the establishment of LR asymmetry (Nonaka et al. 1998; Okada et al. 1999). Ultrastructural studies have shown that monocilia present on cells of the exposed ventral surface of the node rotate in a counterclockwise direction and have been suggested to generate a net leftward flow of extraembryonic fluid known

[Keywords: Nodal; node; left-right asymmetry; isomerism; lateral plate mesoderm; mouse]

Present addresses: ${ }^{1}$ Centre for Genome Research, University of Edinburgh, Edinburgh, EH9 3JQ, UK.; ${ }^{2}$ Medical Research Council Mammalian Genetics Unit, Harwell, Oxfordshire, OX11 0RD, UK.

${ }^{3}$ Corresponding author.

E-MAIL ejrobert@fas.harvard.edu; FAX (617) 496-6770.

Article and publication are at http://www.genesdev.org/cgi/doi/10.1101/ gad.1016202. as the nodal flow (Sulik et al. 1994; Nonaka et al. 1998). Laterality defects documented in several mouse mutants that lack cilia, or whose cilia motility is compromised, have lead to the hypothesis that the nodal flow results in the localized accumulation of morphogen(s) on the left side of the node, thereby initiating the LR signaling cascade (Hamada et al. 2002). In keeping with this, artificially reversing the direction of nodal flow in cultured embryos is sufficient to reverse situs (Nonaka et al. 2002). Surgical ablation of the node (Davidson et al. 1999) and mutations affecting node formation (Dufort et al. 1998) both lead to embryonic laterality defects, implying that the node functions as a signaling center during LR axis formation. The node gives rise to midline structures such as the notochord and floor plate that act as a midline barrier necessary for maintaining correct laterality (Dufort et al. 1998; King et al. 1998; Meno et al. 1998). The midline barrier is proposed to prevent interference between the distinct signaling cascades on either side of the embryo. For example, in Lefty1 mutant embryos, loss of Leftyl from the floor plate compromises the barrier, leading to bilateral Nodal expression in the lateral plate mesoderm and ultimately left isomerisms of the viscera (Meno et al. 1998).

Nodal is required in the pregastrulation embryo to establish the anterior-posterior axis (Brennan et al. 2001). Nodal expression at the extreme lateral edges of the ventral node (Collignon et al. 1996; Lowe et al. 1996) also make it an ideal candidate morphogen asymmetrically localized by the nodal flow to activate left-sided gene expression. However, this possibility has been impossible to test because Nodal mutant embryos arrest prior to primitive streak formation. Elegant studies in zebrafish have shown that a Nodal homolog, Squint, is capable of acting as a classical morphogen, influencing the fate of cells at a distance from the source of Squint production (Chen and Schier 2001). Here we investigated whether Nodal signals from the node similarly act on adjacent cell populations, by genetically removing Nodal activity from cells within the node. Strikingly, embryos lacking Nodal in the node exhibit an array of abnormalities consistent with defects in specification of the LR axis. The loss of Nodal within the node disrupts molecular asymmetry in the left lateral plate mesoderm (LPM). These findings strongly suggest that Nodal acts as a longrange morphogen. In addition, cell lineage studies demonstrate that Nodal acts locally to pattern the node-derived lineage, the notochord, which consequently induces the midline barrier.

\section{Results and Discussion}

At the 4-5-somite stage, Nodal expression becomes transiently asymmetric in the node with increased numbers of cells expressing Nodal on the left versus the right side (Collignon et al. 1996). A 2.7-kb region upstream of the Nodal locus directs expression in the initial symmetrical domain (Fig. 1D; Norris and Robertson 1999). We further mapped this node enhancer to a 350-bp fragment that is sufficient to direct Nodal expression in the nodes of transgenic mice (Fig. 1E). Removal of this 350-bp sequence from the $2.7-\mathrm{kb}$ transgene largely abolishes expression in the node (Fig. 1F). Weak punctate expression seen in more central ventral cells of the node potentially 


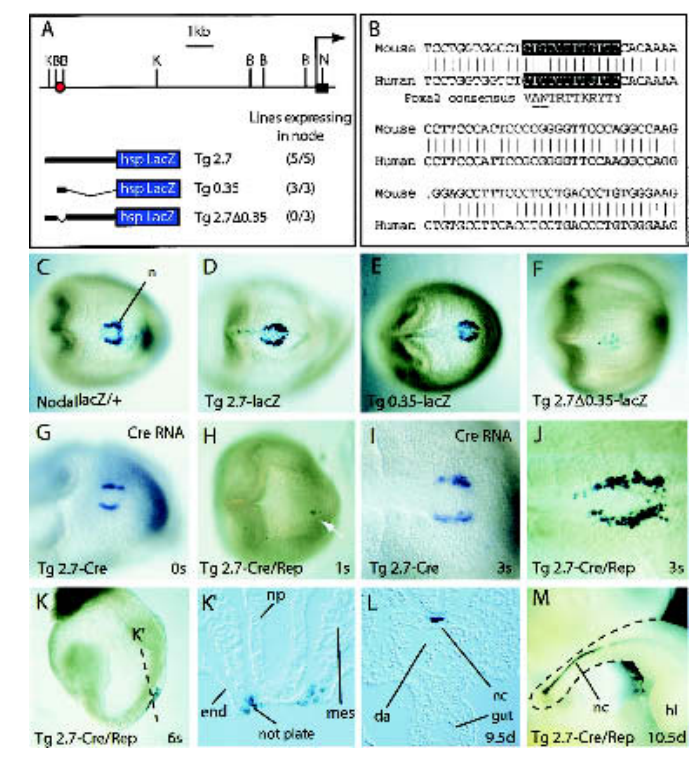

Figure 1. Characterization of the Nodal node enhancer. Ventral $(C-J)$ and lateral $(K)$ views of approximately 8.0-d embryos at the various somite (s) stages indicated. (A) Map of Nodal locus illustrating location of node enhancer element (red circle) and three LacZ reporter constructs used to make stable transgenic lines. Black box indicates position of exon 1 (K, Kpn I; B, Bgl II; N, Not I). (C) Nodal is expressed in the outermost ventral cells of the node at the 2-somite stage as assessed by the Nodal ${ }^{1 a c Z}$ reporter allele. Transgenic lines containing $2.7 \mathrm{~kb}(A, D)$ and $0.35 \mathrm{~kb}(A, E)$ of Nodal genomic sequence express $\beta$-gal reporter in the outermost ventral cells of the node. Removal of the $0.35 \mathrm{~kb}$ from the $2.7-\mathrm{kb}$ transgene eliminates $\beta$-gal expression from the outermost cells of the node $(A, F)$; some staining is seen in the central cells of the node. $(B)$ Partial sequence of the minimal $0.35-\mathrm{kb}$ fragment that drives Nodal expression in the node. Alignment of mouse and human sequences showing predicted Foxa2 binding site. Mismatches between the second and third bases and the Foxa2 consensus are compatible with Foxa2 binding (Overdier et al. 1994). (G) Whole-mount in situ hybridization showing Cre expression in the node of a transgenic line expressing Cre under the control of $\mathrm{Tg} 2.7$ (the 2.7-kb node element). ( $H$ ) Embryo carrying the Tg 2.7-Cre transgene and an allele of the Rosa-26 conditional reporter. Only a few cells show $\beta$-gal activity in the node (white arrow). At the 3-somite stage, Cre mRNA is expressed in the node (I), and Cre activity is detected throughout the outermost ventral cells of the node as visualized by $\beta$-gal activity $(J)$. By the 6 -somite stage, descendants of Nodal-expressing cells in the node are found exclusively in the notochordal plate $\left(K^{\prime}\right)$. By $9.5 \mathrm{~d}(L)$ and $10.5 \mathrm{~d}(M)$, the node descendants are found in the notochord posterior to the hindlimb. No descendants are found in the gut or floor plate.

reflects the presence of a repressor element within the 350 -bp region that normally downregulates Nodal expression in this subpopulation. Alignment of this 350-bp minimal enhancer with the corresponding region from the human Nodal locus identifies a 110-bp stretch that shares $87 \%$ identity (Fig. 1B), including a predicted binding site for Foxa2 (Hnf $3 \beta)$, a member of the forkhead family of transcription factors expressed throughout the ventral cells of the node (Sasaki and Hogan 1993). The lack of Nodal expression in chimeric embryos generated from Foxa2 null ES cells (Dufort et al. 1998), and the pronounced genetic interaction between Foxa2 and Nodal (Collignon et al. 1996; Varlet et al. 1997) provide evidence that Foxa2 acts as an upstream activator of Nodal expression in the node.

Previous fate mapping experiments using the lipophilic dye DiI suggest that the ventral layer of the node gives rise to multiple cell types including notochord, the floor plate of the neural tube, and the definitive endoderm (Beddington 1994; Sulik et al. 1994; Kinder et al. 2001). Here we have exploited an in vivo cell marking system to precisely map the fate of cells expressing Nodal in the node. Transgenic mice were generated that express Cre recombinase under the control of the $2.7-\mathrm{kb}$ node enhancer (Fig. 1G). These Nodal-Cre transgenic mice (Tg 2.7-Cre) were crossed to the Rosa-26 conditional reporter strain carrying a silent $L a c Z$ reporter allele that is specifically activated in cells expressing Crerecombinase (Soriano 1999). As assessed by wholemount in situ analysis of a panel of embryos $(\mathrm{n}=15), \mathrm{Tg}$ 2.7-Cre directs Cre expression in the node at the 0-somite stage. However, $\beta$-gal activity is consistently not detected until the 2-3-somite stage, indicating an approximately 3 -h time delay between Cre transcription and reporter activity (Fig. $1 \mathrm{H}, \mathrm{J})$. Analysis of reporter embryos at various stages of development confirms that the ventral node cells are relatively quiescent, as few descendants are labeled despite rapid growth at these embryonic stages (Bellomo et al. 1996). Although the lag in reporter activity compared to Cre expression makes it difficult to precisely delineate the anterior extent of notochord colonization by derivatives of the node, we only see labeled cells caudal to the hindlimb buds. Contrary to previous DiI labeling experiments, our data show that descendants of the outermost cells of the ventral node exclusively colonize the posterior notochord and do not contribute to either the floor plate or definitive endoderm (Fig. 1L,M).

To test whether Nodal activity is required during specification of the notochord lineage, we designed a strategy to specifically eliminate expression from the node. The $2.7-\mathrm{kb}$ enhancer region was thus deleted by homologous recombination, and correctly targeted ES cells were used to generate germline chimeras (Fig. 2). Mice heterozygous for the $2.7-\mathrm{kb}$ deletion $\left(\mathrm{Nodal}^{\Delta /+}\right)$ are viable and fertile. Moreover, intercross matings yielded
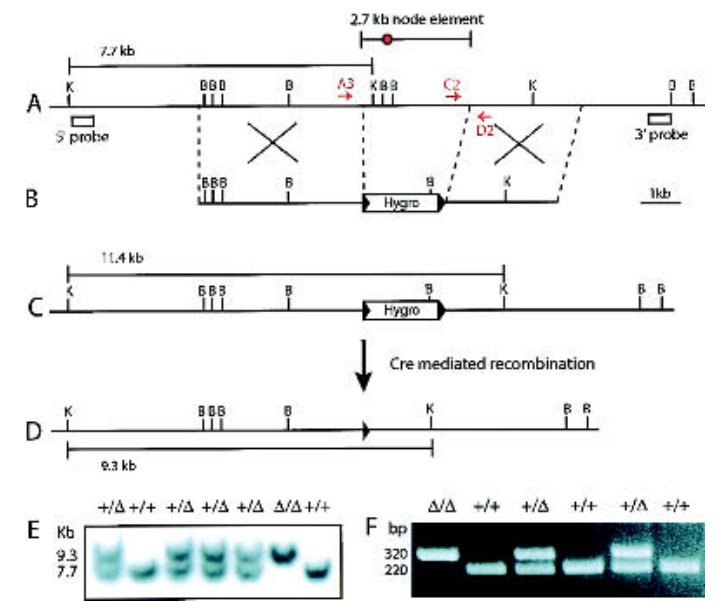

Figure 2. Targeted deletion of the Nodal node enhancer. (A) Map of Nodal genomic locus. $(B)$ Targeting vector designed to replace $2.7 \mathrm{~kb}$ of Nodal sequence with a single loxP site (black triangle). (C) Targeted allele. $(D)$ Recombined allele after Cre-mediated excision of the hygro selection cassette. (E) Southern hybridization of KpnIdigested DNA prepared from tail biopsies of heterozygous intercross offspring at weaning. DNA was hybridized with a 5' external probe (A). (F) PCR analysis of yolk sac DNA prepared from 8.0-dpc embryos. Primers C2/D2 amplify a wild-type band of $220 \mathrm{bp}$, and primers A3/D2 amplify a 320-bp mutant band. K, KpnI; B, BglII. 
Table 1. Breeding data for Nodal ${ }^{\Delta}$ allele

\begin{tabular}{|c|c|c|c|c|c|c|c|}
\hline A & Cross & Stage & $\mathrm{n}$ & $+/+$ & \multicolumn{2}{|c|}{ Nodal $^{+/ \Delta}$} & $\operatorname{Nodal}^{\Delta / \Delta}$ \\
\hline & Nodal $^{+/ \Delta}$ X Nodal ${ }^{+/ \Delta}$ & $\mathrm{P} 21$ & 110 & $22(20 \%)$ & \multicolumn{2}{|c|}{$59(54 \%)$} & $29(26 \%)$ \\
\hline \multirow[t]{3}{*}{$\mathrm{B}$} & Cross & Stage & $\mathrm{n}$ & $+/+$ & Nodal $^{+/-}$ & $\operatorname{Nodal}^{+/ \Delta}$ & Nodal $^{\Delta /-}$ \\
\hline & $\mathrm{Nodal}^{+/ \Delta} \mathrm{X} \mathrm{Nodal}^{+/-}$ & $\mathrm{P} 21$ & 40 & $15(37 \%)$ & $13(33 \%)$ & $12(30 \%)$ & 0 \\
\hline & Nodal $^{+/ \Delta} \mathrm{X} \mathrm{Nodal}^{+/-}$ & $\mathrm{P} 1$ & 33 & $8(24 \%)$ & $4(12 \%)$ & $11(33 \%)$ & $10(30 \%)^{\mathrm{a}}$ \\
\hline
\end{tabular}

$\mathrm{P}$, postnatal day of development

${ }^{a}$ All pups die within first few hours of birth.

Nodal $^{\Delta / \Delta}$ homozygous offspring at Mendelian frequencies (Table 1A). Transcripts were examined by wholemount in situ to confirm that removal of the $2.7-\mathrm{kb}$ node enhancer element eliminates Nodal expression from this tissue. Nodal expression was unaffected during early gastrulation stages (data not shown). By early somite stages, however, node expression was greatly diminished but not completely eliminated, implicating additional as yet unmapped regulatory element/s) (Fig. 4B, see below). Alternatively, residual expression may reflect the activity of the intronic Foxh1-dependent feedback enhancer (Norris and Robertson 1999), which we showed to be responsible for the asymmetric expression of Nodal in the node (Norris et al. 2002). This feedback enhancer directs barely detectable levels of reporter expression in the node (J. Brennan, D. Norris, and E. Robertson, unpubl.). Although expression of Nodal in the node is markedly attenuated in Nodal ${ }^{\Delta / \Delta}$ embryos, robust levels of Nodal expression in the left LPM (Fig. 4G, see below) allow mutant embryos to develop with normal situs.

We previously documented a highly dose-dependent requirement for Nodal signaling during anterior-posterior axis formation (Norris et al. 2002). In these experiments, reduced levels of Nodal signaling in the left LPM failed to activate Lefty2 yet still allowed activation of Pitx2. To test for similar dosage effects in the node, we crossed Nodal ${ }^{\Delta /+}$ heterozygotes to mice heterozygous for a null allele $\left(\mathrm{Nodal}^{+/-}\right)$. We found that $\mathrm{Nodal}^{\Delta /-}$ mutants were born at the correct Mendelian ratio but none survived beyond the first few hours of birth (Table 1B). Interestingly, these mutants display an array of abnormalities consistent with defects in specification of the LR axis (Table 2). For example, in wild-type animals the stomach is positioned on the left (Fig. 3A), whereas in $\mathrm{Nodal}^{\mathrm{\Delta} / \mathrm{-}}$ mutants, positioning was randomized with 8 of 11 animals having the stomach positioned on the right (Fig. 3B). Regardless of stomach orientation, spleens in the Nodal ${ }^{\Delta /-}$ mutants were invariably reduced in size compared to control littermates (Fig. 3C,D). LR patterning defects were also evident in the thoracic cavity. Normally, asymmetric branching results in the formation of four lung lobes on the right and a single lobe on the left (Fig. 3E). However, the Nodal ${ }^{\Delta /-}$ mutants consistently present right isomerisms having four lobes on the right and three or four lobes on the left (Fig. 3F). Interestingly, in human laterality syndromes, this right pulmonary isomerism is typically associated with hyposplenia (Kosaki and Casey 1998).

We used expression of $\alpha$-cardiac actin to examine orientation of the heart tube. At $9.0 \mathrm{~d}$, the direction of heart looping was randomized in $\mathrm{Nodal}^{\Delta /-}$ mutants (Fig. $3 \mathrm{G}, \mathrm{H})$. At birth, the apex of the heart normally points to the left side of the thoracic cavity (Fig. 3I). However, in the Nodal ${ }^{\Delta /-}$ mutants the apex of the heart points to the left, the middle (Fig. 3J), or right. Regardless of overall orientation, hearts in Nodal ${ }^{\Delta-}$ animals show multiple abnormalities, including transposition of the major arteries (data not shown) and atrial-septal defects (Fig. 3J). In all mutants examined $(\mathrm{n}=10)$, the major common defect is the development of a common atrial chamber rather than separate left and right atria. This profound cardiac abnormality most likely accounts for the early postnatal lethality of the Nodal ${ }^{\Delta /}$ animals.

To understand the molecular basis of the laterality defects, we examined the expression of a number of LR marker genes by whole-mount in situ hybridization. At the early head fold stage, Nodal is normally expressed at the lateral edges of the notochordal plate (Fig. 4A). Although the nodes of Nodal $^{\Delta /-}$ embryos are morphologically indistinguishable from control littermates (Fig. 4C'; data not shown), Nodal expression was barely, if at all, detectable (Fig. 4C). Next, we used the Nodal lacZ reporter allele (Collignon et al. 1996) to examine the impact of eliminating Nodal expression in the node on the asymmetric expression of Nodal in the left LPM. At the 3-4-somite stage, Nodal lacZ is expressed in the node and the left LPM (Fig. 4D). In contrast, expression of the Nod$\mathrm{al}^{\text {lacZ }}$ reporter is confined to the node and fails to be induced in the LPM of Nodal ${ }^{\Delta / 1 a c Z}$ mutants (Fig. 4E, Table 3). The absence of asymmetric Nodal expression in the LPM was confirmed by analyzing Nodal mRNA levels (Fig. 4F,H).

Table 2. LR asymmetry defects in the viscera of Nodal ${ }^{\Delta /-}$ mutants at birth

\begin{tabular}{|c|c|c|c|c|c|c|c|c|c|}
\hline & \multicolumn{2}{|c|}{ Stomach position } & \multicolumn{2}{|c|}{ Spleen size } & \multicolumn{2}{|c|}{ Lung lobation $^{\mathrm{c}}$} & \multicolumn{3}{|c|}{ Heart apex direction } \\
\hline & Left & Right & Normal & Small & Normal $^{\mathrm{b}}$ & $\mathrm{RI}^{\mathrm{c}}$ & Left & Middle & Right \\
\hline Control $^{\mathrm{a}}$ & $55 / 55$ & 0 & $24 / 24$ & 0 & $55 / 55$ & 0 & $16 / 16$ & 0 & 0 \\
\hline Nodal $^{\Delta /-}$ & $3 / 11$ & $8 / 11$ & 0 & $10 / 10$ & $1 / 14$ & $13 / 14$ & $1 / 6$ & $2 / 6$ & $3 / 6$ \\
\hline
\end{tabular}

${ }^{\mathrm{a} C}$ Controls had one of following genotypes; Wild type, $\mathrm{Nodal}^{+/ \Delta}$ or $\mathrm{Nodal}^{+/-}$

${ }^{\mathrm{b}}$ Normal lungs had a single lobe on left and 4 lobes on right.

${ }^{\mathrm{c}} \mathrm{RI}$; right pulmonary isomerism. 


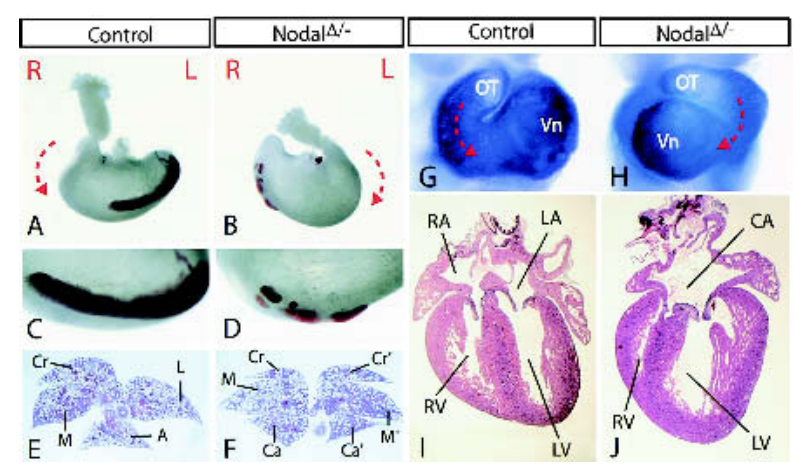

Figure 3. Left-right patterning defects of the viscera of $\mathrm{Nodal}^{\mathrm{\Delta} /-}$ deletion mutants. Organs were dissected from control and deletion pups on the day of birth. Left $(L)$ and right $(R)$ are as indicated in $A$ and $B$. Normally the stomach is situated on the left-hand side of the body $(A)$, but in the deletion mutants the stomach position is randomized such that half the mutants have stomachs on the right $(B)$. The spleen is apposed to the stomach wall $(C)$. In mutants, the spleen is greatly reduced in size $(D)$. In the normal lung, there is one lobe on the left and four on the right $(E)$. In the mutants, there were three or four lobes on both sides, indicating a right pulmonary isomerism $(F)$. At $9.5 \mathrm{~d}$, expression of $\alpha$-cardiac actin mRNA in the heart tube illustrates normal heart looping to the right $(G)$. In $\mathrm{Nodal}^{\Delta /}$ mutants, looping was randomized, with $3 / 7$ showing rightward and $4 / 7$ showing leftward looping $(H)$. In normal littermates, the apex of the heart points to the left $(I)$, yet in mutants the heart apex is ambiguously positioned such that a proportion point to the left, some to the middle $(J)$, and others to the left. Sections through mutant hearts reveal septation defects between the two atria $(J)$. A, accessory lobe; $\mathrm{CA}$, common atrium; $\mathrm{Ca}$, caudal lobe; $\mathrm{Cr}$, cranial lobe; L, left lobe; LA, left atrium; LV, left ventricle; M, medial lobe; $\mathrm{OT}$, outflow tract; RA, right atrium; RV, right ventricle; Vn, ventricles.

In those $\mathrm{Nodal}^{\Delta /-}$ embryos in which Nodal mRNA is detected, asymmetric expression was retained in the node (Fig. 4H'). Together with the observation that deletion of the Foxh1-dependent enhancer leads to a loss of asymmetric Nodal expression (Norris et al. 2002), these findings confirm that activation of the feedback enhancer is responsible for asymmetric Nodal expression in the node. As suggested by the nodal flow hypothesis, asymmetric movement of fluid across the node potentially leads to local accumulation of Nodal, which in turn upregulates expression via the feedback enhancer. Cerberus is a secreted protein which has been shown to antagonize Nodal signaling in Xenopus assays (Piccolo et al. 1999). Nodal signaling on the right edge of the node is likely antagonized by the activity of the Cerberus-related factor Dante, which is expressed more strongly on the right-hand side of the node (Pearce et al. 1999). In combination, right-sided antagonism and the nodal flow potentially amplify differences in Nodal activity across the relatively small area of the node.
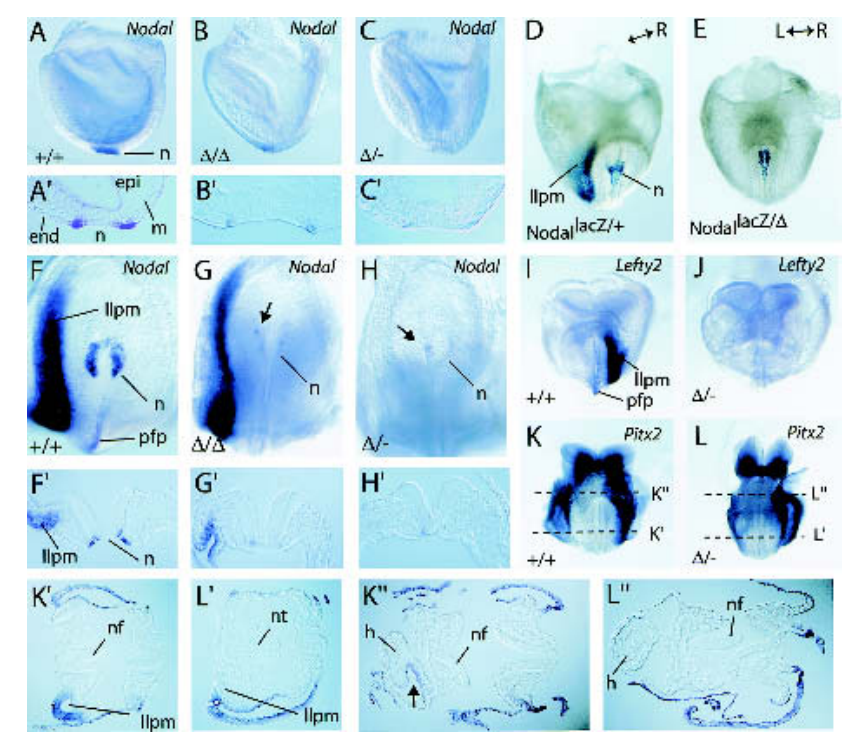

Figure 4. Molecular asymmetry is not established in the lateral plate mesoderm of Nodal ${ }^{\Delta /-}$ deletion mutants. Whole-mount in situ hybridization $(A-C, F-L)$ and LacZ reporter staining $(D, E)$ of 7.5 -d $(A-C)$ and 8.0-d $(D-L)$ embryos. Lateral views with anterior to the left $(A-C)$, caudal views $(D-H)$, and rostral views $(I-L)$ are shown. At the late head fold stage, Nodal is expressed in the node at the distal tip of the embryo $(A)$; transverse sections through the node show that Nodal is expressed in the outermost ventral cells $\left(A^{\prime} ; \mid\right)$. In embryos homozygous for the Nodal ${ }^{\Delta / \Delta}$ allele, Nodal expression is downregulated in the node $(B)$. In embryos trans-heterozygous for the deletion allele and a Nodal null allele $\left(\right.$ Nodal $\left.^{\Delta /-}\right)$, Nodal expression is either entirely absent or negligible in the node $(C)$. Control embryos between 2 and 8 somites express the Nodal ${ }^{1 a c Z}$ reporter in the node and the left LPM $(D)$. In embryos carrying a copy of the deletion allele and the Nodal null reporter allele (Nodal ${ }^{\left.\Delta / L_{\text {LacZ }}\right)}$, Nod$a l^{\text {lacz }}$ is only expressed in the node $(E)$. Similarly Nodal mRNA is expressed in the node and left LPM in control embryos $(F)$, but in Nodal $^{\Delta / \Delta}$ homozygotes, low levels of Nodal are detected in the node yet normal levels of Nodal expression are observed in the left LPM $(G)$. Reduced Nodal expression levels are also found in Nodal ${ }^{\Delta /-}$ nodes, and Nodal expression is absent from the left LPM $\left(H^{\prime}\right)$. Lefty2 is expressed in the left LPM and the left prospective floor plate of control embryos $(I)$ but fails to be induced in either domain in the deletion mutants $(J)$. Pitx2 is expressed in the head mesenchyme, body wall, and left LPM of control embryos $\left(K, K^{\prime} ;\right)$. In the deletion mutants, Pitx2 is expressed in the head mesenchyme and body wall $(L)$ but is absent from the left LPM $\left(L^{\prime}\right)$. Normal expression of Pitx2 in the left-hand side mesenchyme of the developing heart (arrow in $\left.\mathrm{K}^{\prime \prime}\right)$ is absent in the deletion mutants $\left(\mathrm{L}^{\prime \prime}\right)$. llpm, left lateral plate mesoderm; n, node; nf, neural fold; nt, neural tube; pfp, prospective floor plate. Black arrows indicate Nodal expression domain.

Our lineage analysis shows that cells expressing Nodal in the node are destined to form the notochord, the tissue that induces Lefty1 expression in the prospective floor plate (King et al. 1998). Foxa2 and Shh expression

Table 3. Gene expression at the 3-5 somite stage of development

\begin{tabular}{|c|c|c|c|c|c|c|c|c|}
\hline & \multicolumn{2}{|c|}{ Pitx2 } & \multirow{2}{*}{$\frac{\text { Lefty1 }}{\text { PFP }}$} & \multirow{2}{*}{$\frac{\text { Lefty2 }}{\text { PFP + LLPM }}$} & \multicolumn{2}{|c|}{ Nodal } & \multicolumn{2}{|c|}{ Nodal $^{\text {lacz }}$} \\
\hline & LLPM & H. Mes & & & Node & LLPM & Node & LLPM \\
\hline Control $^{\mathrm{a}}$ & $14 / 14$ & $14 / 14$ & $1 / 1$ & $4 / 4$ & $7 / 7$ & $7 / 7$ & $4 / 4$ & $4 / 4$ \\
\hline$N_{o d a l}{ }^{\Delta / \Delta}$ & - & - & - & - & $8^{\mathrm{b}} / 8$ & $8 / 8$ & - & - \\
\hline Nodal $^{\Delta /-}$ & $1^{\mathrm{b}} / 8$ & $8 / 8$ & $0 / 4$ & $0 / 9$ & $2^{b} / 7$ & $0 / 7$ & $6 / 6$ & $0 / 6$ \\
\hline
\end{tabular}

LLPM, left lateral plate mesoderm; H. Mes, head mesenchyme; PFP, prospective floor plate.

${ }^{a}$ Controls had one of following genotypes; Wild type, Nodal ${ }^{+/ \Delta}$ or Nodal ${ }^{+/-}$.

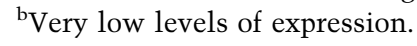


patterns demonstrate the presence of notochord and floor plate in Nodal ${ }^{\Delta /-}$ mutants (data not shown). However, Lefty1 is not expressed in the prospective floor plate of $\mathrm{Nodal}^{\Delta /-}$ mutants (Table 3; data not shown), suggesting that notochord progenitors in the ventral node are not patterned correctly. Alternatively, Nodal in the ventral layer of the node may induce Lefty1 expression in prospective floor plate precursors in the adjacent dorsal layer. Considering that deletion of the Foxh1-dependent enhancer leads to a loss of Lefty1 expression in the midline (Norris et al. 2002), Nodal ${ }^{\Delta /-}$ mutants may fail to induce Lefty 1 as a secondary defect associated with the loss of Nodal expression from the left LPM.

The TGF- $\beta$ family member Lefty 2 is a downstream target of Nodal signaling in the left LPM. As for Nodal, Lefty2 expression requires activation of the Foxh1-dependent enhancer (Saijoh et al. 2000). As predicted by the loss of Nodal signaling in the left LPM of $\mathrm{Nodal}^{\Delta /-}$ mutants, Lefty2 expression is not activated in the LPM of mutants (Fig. 4J). Nodal also induces expression of the homeobox gene Pitx2 in the left LPM (Shiratori et al. 2001). Pitx2 null mutant embryos resemble the $\mathrm{Nodal}^{\Delta /-}$ mutants described here, and similarly exhibit pulmonary right-sided isomerisms, atrial septal defects, and hyposplenia (Gage et al. 1999; Kitamura et al. 1999; Lin et al. 1999; Lu et al. 1999). Pitx2 is not expressed in the left LPM of $\mathrm{Nodal}^{\Delta /-}$ mutants, accounting for the laterality defects seen in some of the visceral organs (Fig. 4K,L). In contrast to the Pitx 2 mutants, cardiac looping is randomized in $\mathrm{Nodal}^{\Delta /-}$ mutants. Thus downstream targets of Nodal signaling, other than Pitx2, likely control some aspects of organ laterality such as cardiac looping.

Transduction of Nodal signaling often requires the presence of a Nodal coreceptor of the EGF-CFC family on the recipient cell (Yeo and Whitman 2001). Animals carrying a null mutation in the EGF-CFC gene, Cryptic, exhibit laterality defects resembling those described here for Nodal ${ }^{\Delta /-}$ embryos (Gaio et al. 1999; Yan et al. 1999). Nodal expression in Cryptic mutants is unaffected in the node but fails to be induced in the left LPM. We suggest that Cryptic selectively amplifies Nodal activity in the node. Another possibility is that Cryptic allows cells to sense a long-range Nodal signal in the LPM. Loss of GDF-1, a TGF- $\beta$ ligand expressed in both the node and the LPM, also causes laterality defects (Rankin et al. 2000). GDF-1 expression is unaffected in the Nodal ${ }^{\Delta /-}$ mutants (data not shown). An intriguing possibility is that Nodal and GDF-1, coexpressed in the node, may form heterodimers with distinct properties. Such an interaction has not yet been shown for GDF-1, but Nodal is capable of forming heterodimers with another TGF- $\beta$ ligand, Bmp7 (Yeo and Whitman 2001). Alternatively, cross-talk between Nodal and GDF-1 signaling pathways in the node and/or LPM may enhance activation of downstream targets.

The ability of Nodal to act as a diffusible morphogen relaying a signal from the node to the LPM is unexpected, because previous studies suggest that the mature processed protein is unstable (Constam and Robertson 1999|. However, Squint, a Nodal homolog in zebrafish, can signal over 6-8 cell diameters /Chen and Schier 2001). Moreover, studies of Lefty2 mutant mice suggest that long-range Nodal signaling activity is normally restricted by the feedback inhibitor Lefty2 (Meno et al. 2001). The mechanism for long-range activity is thought to be diffusion involving endocytosis (Sakuma et al.
2002). Alternatively, long-range Nodal signaling could involve a relay mechanism involving other unidentified molecules.

\section{Materials and methods}

\section{Transgenic and targeted mouse strains}

Transgenes were generated by introducing Nodal genomic sequences into the hsp68lacZpA reporter construct (Sasaki and Hogan 1996). Tg 2.7 contains a 2.7-kb BamH1-Spel fragment located approximately $7 \mathrm{~kb}$ upstream of Nodal coding exon 1 . Tg 0.35 contains a 350-bp BglII fragment from $\mathrm{Tg}$ 2.7. Transgenic mice were produced as previously described (Norris and Robertson 1999).

The targeting construct for the node enhancer deletion $\left(\mathrm{Nodal}^{\Delta}\right)$ contains a 4.1-kb (EcoRI-SpeI) 5' homology arm and a 2.8-kb (BamHI-BamHI) 3'homology arm. The homology arms were cloned into a plasmid containing a loxP-flanked hygro selection cassette. The hygro cassette was excised from targeted ES cell lines by transient transfection of the pMC13-cre plasmid. Mice containing the $\Delta 2.7$ mutation were genotyped using the following primers: A3 (TGAACTCATGACCATCCTCC), C2 (CTGAGTGCTGGGATTATACC), and D2 (TTGCGAGCAATAGTCT CAGC).

Histology and RNA in situ hybridization

Embryos were genotyped prior to whole-mount in situ analysis by yolk sac PCR analysis.

Probes and protocols used for whole-mount in situ were as described (Norris et al. 2002).

\section{Acknowledgments}

We thank Liz Bikoff, Ray Dunn, and Cindy Lu for critical comments on the manuscript. This work was funded by the NIH (to E.J.R.) and supported by a Wellcome Prize Travelling Research Fellowship from the Wellcome Trust (J.B).

The publication costs of this article were defrayed in part by payment of page charges. This article must therefore be hereby marked "advertisement" in accordance with 18 USC section 1734 solely to indicate this fact.

\section{References}

Beddington, R.S.P. 1994. Induction of a second neural axis by the mouse node. Development 120: 613-620.

Beddington, R.S.P. and Robertson, E.J. 1999. Axis development and early asymmetry in mammals. Cell 96: 195-209.

Bellomo, D., Lander, A., Harragan, I., and Brown, N.A. 1996. Cell proliferation in mammalian gastrulation: The ventral node and notochord are relatively quiescent. Dev. Dyn. 205: 471-485.

Brennan, J., Lu, C.C., Norris, D.P., Rodriguez, T.A., Beddington, R.S.P., and Robertson, E.J. 2001. Nodal signaling in the epiblast patterns the early mouse embryo. Nature 411: 965-969.

Capdevila, J., Vogan, K.J., Tabin, C.J., and Izpisua Belmonte, J.C. 2000 Mechanisms of left-right determination in vertebrates. Cell 101: 9-21.

Chen, Y. and A.F. Schier. 2001. The zebrafish Nodal signal Squint functions as a morphogen. Nature 411: 607-610.

Collignon, J., I. Varlet, and E.J. Robertson. 1996. Relationship between asymmetric nodal expression and the direction of embryonic turning. Nature 381: 155-158.

Constam, D.B. and Robertson, E.J. 1999. Regulation of bone morphogenetic protein activity by pro domains and proprotein convertases. $I$. Cell. Biol. 144: 139-149.

Davidson, B.P., Kinder, S.J., Steiner, K., Schoenwolf, G.C., and Tam, P.P.L. 1999. Impact of node ablation on the morphogenesis of the body axis and the lateral asymmetry of the mouse embryo during early organogenesis. Dev. Biol. 211: 11-26.

Dufort, D., Schwartz, L., Harpal, K., and Rossant, J. 1998. The transcription factor HNF3beta is required in visceral endoderm for normal primitive streak morphogenesis. Development 125: 3015-3025.

Gage, P.J., Suh, H., and Camper, S.A. 1999. Dosage requirement of Pitx2 for development of multiple organs. Development 126: 4643-4651. 
Gaio, U., Schweickert, A., Fischer, A., Garratt, A.N., Muller, T., Ozcelik, C., Lankes, W., Strehle, M., Britsch, S., Blum, M., et al. 1999. A role of the cryptic gene in the correct establishment of the left-right axis. Curr. Biol. 9: 1339-1342.

Hamada, H., Meno, C., Watanabe, D., and Saijoh, Y. 2002. Establishment of vertebrate left-right asymmetry. Nat. Rev. Genet. 3: 103-113.

Kinder, S.J., Tsang, T.E., Wakamiya, M., Sasaki, H., Behringer, R.R., Nagy, A., and Tam, P.P.L. 2001. The organizer of the mouse gastrula is composed of a dynamic population of progenitor cells for the axial mesoderm. Development 128: 3623-3634.

King, T., Beddington, R.S.P., and Brown, N.A. 1998. The role of the brachyury gene in heart development and left-right specification in the mouse. Mech. Dev. 79: 29-37.

Kitamura, K., Miura, H., Miyagawa-Tomita, S., Yanazawa, M., KatohFukui, Y., Suzuki, R., Ohuchi, H., Suehiro, A., Motegi, Y., Nakahara Y., et al. 1999. Mouse Pitx2 deficiency leads to anomalies of the ventral body wall, heart, extra- and periocular mesoderm and right pulmonary isomerism. Development 126: $5749-5758$.

Kosaki, K. and Casey, B. 1998. Genetics of human left-right axis malformations. Semin. Cell Dev. Biol. 9: 89-99.

Lin, C.R., Kioussi, C., O'Connell, S., Briata, P., Szeto, D., Liu, F., IzpisuaBelmonte, J.C., and Rosenfeld, M.G. 1999. Pitx2 regulates lung asymmetry, cardiac positioning and pituitary and tooth morphogenesis. Nature 401: 279-282.

Lowe, L.A., Supp, D.M., Sampath, K., Yokoyama, T., Wright, C.V., Potter, S.S., Overbeek, P., and Kuehn, M.R. 1996. Conserved left-right asymmetry of nodal expression and alterations in murine situs inversus. Nature 381: 158-161.

Lu, M.F., Pressman, C., Dyer, R., Johnson, R.L., and Martin, J.F. 1999. Function of Rieger syndrome gene in left-right asymmetry and craniofacial development. Nature 401: 276-278.

Meno, C., Shimono, A., Saijoh, Y., Yashiro, K., Mochida, K., Ohishi, S., Noji, S., Kondoh, H., and Hamada, H. 1998. lefty-1 is required for left-right determination as a regulator of lefty-2 and nodal. Cell $\mathbf{9 4}$ 287-297

Meno, C., Takeuchi, J., Sakuma, R., Koshiba-Takeuchi, K., Ohishi, S. Saijoh, Y., Miyazaki, J., ten Dijke, P., Ogura, T., and Hamada, H. 2001. Diffusion of nodal signaling activity in the absence of the feedback inhibitor Lefty2. Dev. Cell 1: 127-138.

Nonaka, S., Tanaka, Y., Takeda, S., Harada, A., Kanai, Y., Kido, M., and Hirokawa, N. 1998. Randomization of left-right asymmetry due to loss of nodal cilia generating leftward flow of extraembryonic fluid in mice lacking KIF3B motor protein. Cell 95: 829-837.

Nonaka, S., Shiratori, H., Saijoh, Y., and Hamada, H. 2002. Determination of left-right patterning of the mouse embryo by artificial nodal flow. Nature 418: 96-99.

Norris, D.P. and Robertson, E.J. 1999. Asymmetric and node-specific nodal expression patterns are controlled by two distinct cis-acting regulatory elements. Genes \& Dev. 13: 1575-1588.

Norris, D.P, Brennan, J., Bikoff, E.K., and Robertson, E.J. 2002. The FoxH1 dependent autoregulatory enhancer controls the level of Nodal signals in the mouse embryo. Development 129: 3455-3468.

Okada, Y., Nonaka, S., Tanaka, Y., Saijoh, Y., Hamada, H., and Hirokawa, N. 1999. Abnormal nodal flow precedes situs inversus in iv and inv mice. Mol. Cell 4: 459-468.

Overdier, D.G., Porcella, A., and Costa, R.H. 1994. The DNA-binding specificity of the hepatocyte nuclear factor $3 /$ forkhead domain is influenced by amino-acid residues adjacent to the recognition helix. Mol. Cell Biol. 14: 2755-2766.

Pearce, J.J., Penny, G., and Rossant, J. 1999. A mouse cerberus/Dan related gene family. Dev. Biol. 209: 98-110.

Piccolo, S., Agius, E., Leyns, L., Bhattacharyya, S., Grunz, H., Bouwmeester, T., and De Robertis, E.M. 1999. The head inducer Cerberus is a multifunctional antagonist of Nodal, BMP and Wnt signals. $\mathrm{Na}$ ture 397: 707-710.

Rankin, C.T., Bunton, T., Lawler, A.M., and Lee, S.J. 2000. Regulation of left-right patterning in mice by growth/differentiation factor-1. Nat Genet. 24: 262-265

Saijoh, Y., Adachi, H., Sakuma, R., Yeo, C.Y., Yashiro, K., Watanabe, M., Hashiguchi, H., Mochida, K., Ohishi, S., Kawabata, M., et al. 2000 Left-right asymmetric expression of lefty2 and nodal is induced by a signaling pathway that includes the transcription factor FAST2. Mol. Cell 5: $35-47$.
Sakuma, R., Ohnishi Yi, Y., Meno, C., Fujii, H., Juan, H., Takeuchi, J., Ogura, T., Li, E., Miyazono, K., and Hamada, H. 2002. Inhibition of Nodal signaling by Lefty mediated through interaction with common receptors and efficient diffusion. Genes Cells 7: 401-412.

Sasaki, H. and Hogan, B.L.M. 1993. Differential expression of multiple fork head related genes during gastrulation and axial pattern formation in the mouse embryo. Development 118: 47-59.

- 1996. Enhancer analysis of the mouse HNF-3 beta gene: Regulatory elements for node/notochord and floor plate are independent and consist of multiple sub-elements. Genes Cells 1: 59-72.

Shiratori, H., Sakuma, R., Watanabe, M., Hashiguchi, H., Mochida, K. Sakai, Y., Nishino, J., Saijoh, Y., Whitman, M., and Hamada, H. 2001 Two-step regulation of left-right asymmetric expression of Pitx2: Initiation by nodal signaling and maintenance by Nkx2. Mol. Cell 7: 137-149.

Soriano, P. 1999. Generalized lacZ expression with the ROSA26 Cre reporter strain. Nat. Genet. 21: 70-71.

Sulik, K., Dehart, D.B., Iangaki, T., Carson, J.L., Vrablic, T., Gesteland, K., and Schoenwolf, G.C. 1994. Morphogenesis of the murine node and notochordal plate. Dev. Dyn. 201: 260-278.

Varlet, I., Collignon, J., Norris, D.P., and Robertson, E.J. 1997. Nodal signaling and axis formation in the mouse. Cold Spring Harb. Symp. Quant. Biol. 62: 105-113.

Yan, Y.T., Gritsman, K., Ding, J., Burdine, R.D., Corrales, J.D., Price, S.M., Talbot, W.S., Schier, A.F., and Shen, M.M. 1999. Conserved requirement for EGF-CFC genes in vertebrate left-right axis formation. Genes \& Dev. 13: 2527-2537.

Yeo, C. and Whitman, M. 2001. Nodal signals to Smads through Criptodependent and Cripto-independent mechanisms. Mol. Cell 7: 949957. 


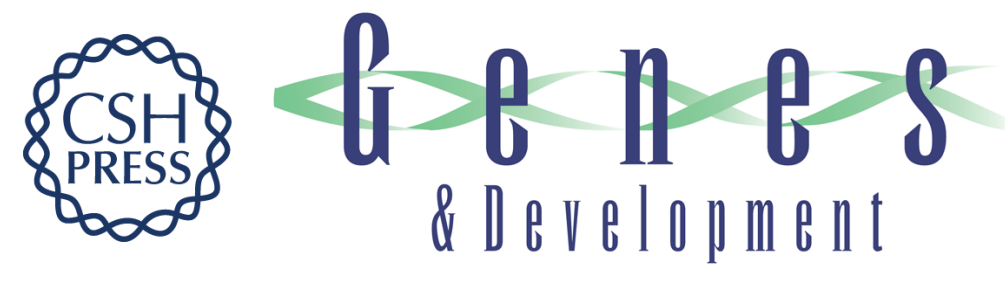

\section{Nodal activity in the node governs left-right asymmetry}

Jane Brennan, Dominic P. Norris and Elizabeth J. Robertson

Genes Dev. 2002, 16:

Access the most recent version at doi:10.1101/gad.1016202

References This article cites 41 articles, 12 of which can be accessed free at: http://genesdev.cshlp.org/content/16/18/2339.full.html\#ref-list-1

License

Email Alerting Receive free email alerts when new articles cite this article - sign up in the box at the top Service right corner of the article or click here.

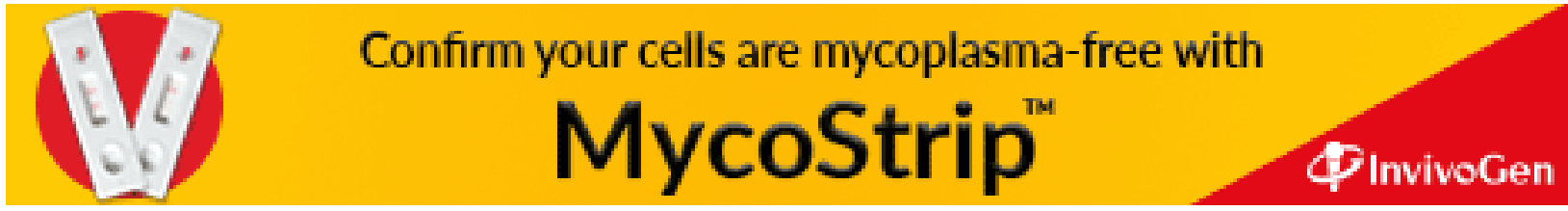

